\title{
Em direção à cura: confrontando o Holocausto por meio do Psicodrama, do Sociodrama e dos Rituais
}

\author{
Towards Healing: Confronting the Holocaust through Psychodrama, \\ Sociodrama and Rituals
}

\section{Hacia la curación: afrontando el Holocausto a través del Psicodrama, Sociodrama y Rituales}

\author{
Yaacov Naor \\ Psychodrama and Intermodal Expressive Arts Therapy Centre (EAT) - email: yaacovn@gmail.com \\ Hilde Goett \\ Psychodrama Institute for Europe (PIfE) - email: hildegoett@t-online.de
}

\section{Resumo}

Este artigo descreve: um projeto de workshops realizados com descendentes da segunda e da terceira gerações de sobreviventes do Holocausto e dos agressores; a transmissão transgeracional do trauma, identificando as diferenças e as semelhanças entre a vítima e os descendentes de agressores, bem como aqueles de origem mista; e como o Psicodrama, o Sociodrama e o ritual são usados para criar o encontro, o diálogo e o começo da cura.

Palavras-chave: Holocausto. Psicodrama. Reconciliação. Sociodrama. Trauma transgeracional.

\section{Abstract}

This text describes an on-going workshop project undertaken with second and third generation descendants of Holocaust survivors and perpetrators. The trans-generational transmission of trauma, differences and commonalities between victim and perpetrator descendants as well as those from mixed backgrounds are discussed. The use psychodrama, Sociodrama and rituals to bring about encounter, dialogue and the beginnings of healing are discussed.

Keywords: Holocaust. Psychodrama. Reconciliation. Sociodrama. Trans-generational trauma.

\section{Resumen}

Este texto describe un proyecto continuado de talleres realizados con descendientes de la 
segunda y tercera generación de supervivientes y perpetradores del Holocausto. Examinan la transmisión transgeneracional del trauma e identifican semejanzas y diferencias entre los descendientes de las víctimas y de los perpetradores, así como de aquellos con orígenes mixtos. Exponen como usan el psicodrama, el Sociodrama y los rituales para producir el encuentro, el diálogo y el comienzo de la curación.

Palabras-clave: Holocausto. Psicodrama. Sociodrama. Reconciliación. Trauma transgeneracional.

\section{INTRODUÇÃO}

Desde 1995, os autores foram conjuntamente envolvidos em um projeto especial de workshop psicodramático, projetado para os descendentes da segunda e da terceira gerações de vítimas do Holocausto e dos agressores. O propósito foi ajudar os participantes a reconhecer e compreender as implicações morais, sociais e pessoais do Holocausto.

Os diretores do Psicodrama vieram de lados opostos do Holocausto, o que torna essa experiência única e especial, pois trazem com eles a história e o legado de suas famílias. Yaacov Naor é filho de dois sobreviventes do Holocausto. Nasceu em 1948 em um campo de desabrigados no sul da Alemanha e se mudou com seus pais para Israel com um ano de idade. Hilde Goett nasceu na Romênia em 1953, sua família era parte da minoria alemã naquele país. Ela cresceu em meio ao tumulto: de um lado, ambos os avós serviram no exército nazista, por isso foi discriminada como filha de fascistas; de outro, a avó foi deportada para a Sibéria pelo regime comunista. E quando tinha 20 anos, mudou-se com a família para a Alemanha.

Começaram a coliderar grupos de psicodrama e perceberam que compartilhavam os mesmos objetivos e as motivações. Ambos queriam ensinar as pessoas a ouvir a história do Holocausto para abrir espaço para a diferença e respeitar o outro. Enquanto trabalhavam juntos tornaram-se próximos. Suas famílias se encontraram e lentamente tornaram-se bons amigos. Isso foi possível porque concordavam que o propósito não era alcançar a reconciliação, mas sim ensinar os alemães e os judeus e outros que participavam dos workshops a serem testemunhas das expressões pessoais e únicas dos participantes e criar um diálogo mútuo.

\section{A transmissão transgeracional do trauma}

O interesse profissional pelo conceito do trauma transgeracional e pela transmissão de consequências traumáticas de geração em geração aumentou ao longo dos últimos 20 anos e agora está bem estabelecido. Isso ocorre porque os estudos de caso, os relatórios de psicoterapia e os pesquisadores descobriram que a segunda geração de sobreviventes do Holocausto relatou os mesmos tipos de problemas emocionais e um sofrimento profundo, semelhante aos próprios sobreviventes. Em 1994, Jürgen Müller-Hohagen, que realizou um trabalho psicoterapêutico por muitos anos, publicou seu entendimento sobre a forma como o trauma é transmitido.

Os critérios de diagnóstico do Transtorno de Estresse Pós-Traumático (TEPT), resultante de traumas de guerra, são frequentemente aplicados nos participantes, embora não tenham nenhuma experiência pessoal de guerra. Os profundos sentimentos de vergonha e culpa impedem um debate construtivo sobre a transmissão transgeracional do trauma do agressor. Sabe-se que nunca houve uma investigação na Alemanha. A identificação com o 
poder, o obscurecimento e a redefinição dos agressores como vítimas são algumas das características que são transmitidas nas famílias dos agressores. A fim de parar a transmissão do trauma de geração para geração, é preciso encontrar uma forma acessível e adequada de lidar com o trauma do Holocausto e processá-lo.

Gabriele Rosenthal (1998) investigou a transmissão transgeracional do trauma tanto dos sobreviventes como dos agressores do período nazista. Suas descobertas tiveram uma forte influência sobre esse trabalho. Ela faz perguntas sobre a formação de diálogo nas famílias de ambos os lados, sobre a influência do passado no presente. Rosenthal demonstra ainda como o estilo de vida comum da família, as expectativas diárias de seus membros, os sentimentos de segurança, aceitação e pertencimento resultam das experiências vividas no Holocausto. Ela compara os problemas dos descendentes das vítimas aos problemas dos descendentes dos agressores e identifica as semelhanças e as diferenças.

Um dos pontos comuns que esses grupos de conflito compartilham é o silêncio, mas as motivações são diferentes. Nas famílias agressoras, foi principalmente constatado o medo da caça, da perseguição, da condenação e da execução que leva ao silêncio sobre o Holocausto. Já nas famílias dos sobreviventes, foram constatados a tristeza sentida por familiares assassinados, a vergonha dessa humilhação extrema e o desejo de proteger os descendentes da sombra desses terríveis acontecimentos. Outro ponto comum compartilhado por ambos os lados é o terrível efeito de segredos familiares, que nos sistemas familiares institucionalizados trabalham contra uma consideração temática do passado. Isso se reflete nas fantasias dos descendentes, que expressam esse terrível efeito de muitas formas diferentes. Os descendentes das vítimas colocam questões sobre a culpa da sobrevivência, como "o que os sobreviventes fizeram para sobreviver?". Enquanto os descendentes dos agressores fazem perguntas que implicam culpa, como "o que eu teria feito na mesma situação?".

\section{O cenário do workshop}

O workshop "Enfrentando o Holocausto por meio de Psicodrama, Sociodrama e Rituais" foi oferecido em dois cenários diferentes. O primeiro compreende uma série de seminários de finais de semana em um ciclo de dois a três anos. Estes incluem visitas aos memoriais de Auschwitz e Birkenau e psicodrama no Educational Encounter Center (Centro de Encontro Educacional) em Oswiecim. Em Birkenau, foram realizados rituais criados pelos participantes do grupo, em que oferecem tempo e espaço para discussões e análises e são adequados para pequenos grupos de 15 a 25 participantes. Foram também oferecidos workshops de três horas em congressos e convenções para apresentar um exemplo do trabalho, em que de 30 a 80 participantes, na faixa etária de 22 a 78 anos, podem confrontar e discutir as consequências do Holocausto na atualidade. Nesses workshops, trabalham psicodramatistas e profissionais que estão familiarizados com a teoria de papéis e as técnicas do psicodrama.

\section{Os participantes: os sobreviventes e os agressores}

Os participantes judeus que vêm para os workshops têm alguma ideia sobre o destino de seus familiares durante a Segunda Guerra Mundial, sabem o que realmente aconteceu ou retêm fragmentos que lhes afligem. Eles lamentam os familiares assassinados, a perda de uma família intacta e uma rede social e sentem-se indignados em relação aos agressores que os sobrecarregaram com essa dor sem fim. Querem chegar a algum entendimento dessa dor, desse desespero e desse luto que parecem não ter fim. Os participantes das famílias de agressores expressam sentimentos diferentes. Geralmente, desejam negar sua história familiar, combater os sentimentos de culpa e vergonha e têm dificuldade em distinguir entre a culpa 
pessoal e a coletiva. Buscam também um melhor entendimento de si mesmos e de suas famílias e querem libertar-se de sua identificação como agressores. Muitos cresceram em um estado de medo constante de punição e querem discutir essa questão. Eles também procuram ajuda para chegar a termo com relação ao afeto que sentem por seus pais agressores. Alguns esperam ainda pela redenção ou mesmo pelo perdão. Outros participantes vêm de famílias mistas, porque compartilham as experiências tanto das vítimas como dos agressores. Por exemplo, os cristãos batizados com descendência parcialmente judia e as pessoas de famílias que sofreram perseguição por sua orientação política, religiosa ou sexual. Esses participantes estão muitas vezes angustiados com sua identidade e sua afiliação.

Quanto às diferenças, os participantes do workshop compartilham um espaço comum, e os pontos comuns são investigados nos seminários sem serem generalizados como experiências iguais ou idênticas. O silêncio do Holocausto pesa muito, todos sentem a necessidade de decifrá-lo e sentem-se profundamente envolvidos como indivíduos, membros da família e com relação ao outro lado. Assim, todos os participantes são vistos como traidores por suas famílias, porque traem o tabu do silêncio e buscam discussões abertas e análises. Eles enfrentam a família com seu passado conturbado e são, portanto, vistos como perigosos por outros membros da família, ou melhor, tornam-se os bodes expiatórios, as causas de desastres e acidentes. Dina Wardi (1992), psicanalista de Jerusalém, descreve bodes expiatórios de famílias judias como "velas de comemoração" que criam subjetivismo sobre o Holocausto e sustentam o luto por aqueles que pereceram. Nas famílias agressoras e mistas, aqueles que enfrentam seus familiares com seu passado nazista também são punidos e excluídos por quebrarem o código de silêncio. Eles carregam o medo, a vergonha, a culpa e a responsabilidade pelos pecados da família, da comunidade e do mundo. Os grupos participantes dos workshops são constituídos de bodes expiatórios de todos os lados do conflito: das vítimas, dos agressores e das famílias mistas.

\section{O trabalho: do encontro para o diálogo para cura}

O trabalho é baseado no conceito de Moreno sobre o encontro que pode levar a um diálogo. As atividades incluem psicodrama, sociodrama, ritual, artes e atividades que desenvolvem a consciência, a confiança, a empatia e a aceitação. A preocupação é iniciar discussões pessoais profundamente significativas sobre o palco do psicodrama, para encontrar uma linguagem para isso e ficar ciente das diferentes verdades, visando superar as consequências do trauma coletivo durante o período nazista. Parte-se da premissa de que a experiência da força ou da violência é experimentada de forma inata e de que o trauma fica severamente sedimentado no corpo no qual encontrou seu lugar e é sentido fisicamente.

Os diretores de Psicodrama, como psicodramatistas e defensores de um método orientado para a ação, acreditam que um efeito duradouro ocorre quando a discussão ativa de um sujeito é profundamente sentida e penetra no processo de pensamento, abrindo novos horizontes e iluminando os problemas. Isso significa que, durante o trabalho, o corpo deve ser atentamente envolvido e autodeterminado.

\section{Aquecimento}

O corpo e os exercícios de encontro fazem parte do aquecimento para começar a tornar isso possível e também ajudam a estabelecer contato real entre os participantes do grupo. Utiliza-se de uma larga gama de exercícios em pequenos grupos, com e sem música, que se concentram sobre o corpo e os sentidos. Alguns exercícios são projetados para que os participantes se divirtam em conjunto, se espelhem mutuamente e construam solidariedade, enquanto outros os veem unindo forças para excluir pessoas e separar os grupos. As emoções 
e os instintos dos participantes do contexto de suas vidas reais são ativados por meio desse trabalho, e os participantes que são vítimas, agressores e famílias mistas são capazes de se encontrar e se conhecer. Isso ajuda a criar uma atmosfera de atenção e abertura para lidar com a sensibilidade do assunto em questão.

\section{Psicodrama e Sociodrama}

Como regra, o trauma do período nazista não foi experimentado pessoal nem diretamente pelos participantes dos workshops. Eles não são sobreviventes da Shoa ou do Holocausto, tampouco agressores nazistas, mas seus filhos, netos e membros familiares. Trata-se de trauma transgeracional. Nesses workshops, permite-se que a verdade subjetiva dos respectivos lados seja representada no palco do psicodrama com toda a tristeza, luto, vergonha, desespero, horror, raiva e culpa que isso implica. Assim, constrói-se uma ponte conectando os participantes com as histórias dos familiares de lados opostos.

Usando o Sociodrama, é possível explorar a história da Segunda Guerra Mundial, investigando os elementos que causaram essa violência assustadora, essa dor e destruição na Europa e que levaram a essas mudanças radicais em todo o mundo. São levadas em consideração as consequências para diferentes setores das populações que eram parceiros no conflito. Ao fazer isso, pretende-se facilitar encontros entre descendentes das vítimas e dos agressores e, assim, estabelecer um diálogo para lidar com a carga do trauma herdado das gerações anteriores.

\section{Rituais}

A Segunda Guerra Mundial e o Holocausto são uma história de crueldade, dor e sofrimento que deixou cicatrizes nas vítimas e nos perseguidores. Os vestígios permanecem conosco no presente e o processo é de longa duração. Não importa o quão produtivos os workshops sejam na criação de encontro, de diálogo e de cura, sabe-se que as palavras não podem expressar completa e exatamente as reações dos participantes ao Holocausto. A experiência fenomenológica e a expressão são necessárias. Assim, enquanto estavam em Auschwitz, trabalharam psicodramaticamente no palco, incluíram também um processo de criação ritual individual no Campo da Morte Birkenau.

Uma das experiências mais difíceis dos sobreviventes do Holocausto e de seus descendentes é a ausência de um verdadeiro túmulo de concreto para chorar os mortos. Os rituais são uma parte integral de um evento psicodramático ou sociodramático, porque fornecem concretizações simbólicas. Eles criam uma nova oportunidade para enterrar os mortos, oferecem significado e uma espécie de encerramento para os eventos do passado e podem tomar a forma de serviços religiosos, cerimônias memoriais, sepultamento, leitura de poesia e canto ao lado de um túmulo imaginário. Alguns se tornam peças de teatro que incluem movimento e canto. Todos são apoiados pelo grupo todo, a comunidade é necessária para segurar e conter em esses momentos. O ritual como uma forma de compartilhamento individual psicodramática e sociodramática é um ato terapêutico, que permite aos participantes confrontarem o Holocausto de suas maneiras próprias e únicas, sem julgamento ou culpa. Ele requer o uso da imaginação e da criatividade e dá uma voz, um palco, uma forma para emoções que não foram claramente expressas antes. Cria uma perspectiva, um espaço luminal, uma realidade excedente que existe simultaneamente no passado e no presente, unindo o espaço entre os mundos interno e externo dos participantes. Leva à catarse, à mudança e a um sentido de integração. Alguns rituais se tornaram, para seus criadores, a melhor e a mais profunda forma de enfrentar o Holocausto, por exemplo: andar descalço nos trilhos de ferro que conduzem ao crematório principal; atirar garrafas de vidro na parede do 
alojamento das mulheres; gritar e chorar; ouvir música calma e harmônica dentro de um dos alojamentos; ler o poema de Paul Celan (1995), "Fuga da morte"; partilhar um pão seco dentro de um círculo e comê-lo lentamente; e participar de uma cerimônia onírica de enterro de uma mulher jovem.

Essas cerimônias ritualistas também permitem o compartilhamento de questões pessoais e interpessoais simultaneamente e são, portanto, terapêuticas para todo o grupo. Focam nas expressões de fortes emoções - como raiva, culpa, medo, ansiedade, vergonha, desamparo, desesperança, humilhação - e são, portanto, formas de reconhecimento do sofrimento do outro lado. É criado, então, um equilíbrio entre o indivíduo e o grupo, um tipo de cura psicossocial. As ligações entre os indivíduos, o grupo e a comunidade são fortalecidas.

\section{Em direção à cura e à reconciliação}

Nesses workshops, os participantes investigam maneiras diferentes por meio das quais os papéis de perseguidor e vítima são internalizados nos indivíduos e na sociedade. Eles exploram formas espontâneas e expressivas e modos criativos de lidar com a relação entre agressor e vítima e são incentivados a encontrar "o outro lado".

O trabalho ativo por meio do corpo permite uma abertura segura e imediata do mundo emocional interior e um encontro com a verdade interna. Os participantes compartilham suas memórias, suas experiências, suas fantasias e seus sentimentos e dão voz ao seu sofrimento. Acontece, então, a oportunidade de vencer a luta contra o anonimato, quebrando os hábitos sociais e familiares do silêncio. Os participantes contam e atuam suas histórias e, como resultado, aprendem a enfrentar sua própria história do Holocausto de uma forma genuína.

O trabalho psicodramático, sociodramático e ritual auxilia os participantes a passarem das projeções, das generalizações, dos preconceitos, das preconcepções e das ilusões para o processo de aprendizagem. Os participantes aprendem a ser centrados, assumir responsabilidade, olhar olho no olho, ficar cara a cara com reconhecimento, empatia, respeito e aceitação.

Esses encontros entre os sobreviventes da segunda e terceira gerações do Holocausto e dos agressores são muitas vezes comoventes, frequentemente dolorosos e, às vezes, impossíveis. Essas pessoas corajosas estão correndo o risco de conhecer e confrontar o outro lado de forma segura, trabalhando profundamente sobre esse tema na frente dos outros, no grupo. Uma vez que o trabalho facilita uma experiência intensa para os participantes, há o perigo de criar falsas proximidades que possam levar ao perdão prematuro.

Não se pretende alcançar a reconciliação, mas, às vezes, isso acontece espontânea e naturalmente, passo a passo, em um longo e lento processo. Os participantes são reunidos e unidos por meio desse trabalho e desses rituais. Eles experimentam a esperança, um sentido de pertencimento e alívio da solidão, do anonimato e da opressão pela enormidade do Holocausto.

\section{Reflexões}

Embora os descendentes das vítimas do Holocausto e dos agressores tenham o mesmo direito de representar seus sofrimentos no palco do psicodrama e refletir sobre eles no contexto da história real, isso não significa que os sofrimentos dos dois lados sejam olhados de forma análoga. É muito mais importante encontrar uma maneira de expressão que possa ser manifestada em uma linguagem comum que funcione diametralmente contra as realidades tradicionalizadas da época.

Os diretores de Psicodrama obtiveram êxito na criação de um lugar seguro para uma 
expressão dolorosa, para construir a confiança e desenvolver um sentido de pertencimento. Eles querem que os participantes aceitem o grupo do lado oposto para compartilhar o medo, o ódio e o preconceito para chegar a um encontro real e diálogo genuíno, em que as feridas podem ser sentidas, choradas e depois curadas. Para eles, a extensão da destruição causada pelo poder nazista tornou-se mais completa e a perda do povo judeu e sua cultura mais perceptível. Nesses 15 anos em que trabalham juntos, desenvolveram um sistema de encontro e diálogo, cheio de aceitação mútua, respeito, reconhecimento e amor. Nos verões de 2008 e 2010, realizaram uma nova semana do Seminário Internacional de Psicodrama em Cracóvia e em Auschwitz para participantes de vários países, chamado "Vestígios do Holocausto no presente". Em razão do sucesso e do significado dessa experiência, planejam oferecer novamente esse formato no futuro.

"Confrontando o Holocausto por meio do Psicodrama, do Sociodrama e dos Rituais" é uma experiência dolorosa e purificadora para ambos os lados e, frequentemente, resulta na decisão de viver um futuro honroso e digno. Somos todos, agora, responsáveis por garantir que a história não se repita. A compreensão da dor que se tornou uma parte essencial da vida de uma pessoa pode levar a uma decisão clara de jamais causar essa dor a si mesmo e compreender um relacionamento respeitoso e apaixonado com outras pessoas.

Mais informações sobre o trabalho e os workshops discutidos neste artigo podem ser encontradas no website <http://www.pife-europe.eu> do Psychodrama Institute for Europe (PIfE) (Instituto de Psicodrama para a Europa).

\section{REFERÊNCIAS}

BAR-ON, D. Legacy of Silence: Encounters with Children of the Third Reich. Cambridge: Harvard University Press, 1989.

Fear and Hope: Three Generations of the Holocaust. Cambridge: Harvard University Press, 1995.

BERGMANN, M. S.; JACOVY, M. E. (eds.). Generations of the Holocaust. New York: Columbia University Press, 1990.

CELAN, P. "Death Fugue". In: HILDA, S. (ed.). Holocaust Poetry. New York: St. Martins Griffin, 1995, p. 39.

KELLERMANN, P. F. Sociodrama and Collective Trauma. London: Jessica Kingsley, 2007.

(2009). Holocaust Trauma: Psychological Effects and Treatment. New York. Bloomington: iUniverse, 2009.

KRONDORFER, B. Remembrance and Reconciliation: Encounters Between Young Jews and Germans. New Haven/London: Yale University Press, 1995.

MULLER-HOHAGEN, J. Geschichte in uns. Psychogramme aus dem Altag. München: Kneselbeck Verlags KG, 1994.

NAOR, Y. "The Theater of the Holocaust". In: LEVINE, S.; LEVINE, E. (eds.). Foundations of Expressive Arts Therapy. London: Jessica Kingsley, 1999.

; GOETT, H. "Confronting the holocaust through psychodrama, sociodrama and ritual".

In: WIENER, R.; ADDERLEY, D.; KIRK, K. (eds.). Sociodrama in a Changing World. Lulu.com, 2011.

ROSENTHAL, G. (ed.). The Holocaust in Three Generations: Families of Victims and Perpetrators of the Nazi Regime. London: Cassell, 1998. 
WAJNRYB, R. The Silence: How Tragedy Shapes Talk. Crow's Nest: Allen \& Unwin, 2001. WARDI, D. Memorial Candles: Children of the Holocaust. London: Tavistock, 1992.

WIENER, R. "A Sociodramatist Goes to Work". In: CHESNER, A.; HAHN, H. (eds.). Creative Advances in Groupwork. London: Jessica Kingsley, 2001.

Recebido: 14/02/2016

Aceito: 11/03/2016

Yaacov Naor (MA, GAC, TEP), filho de dois sobreviventes do Holocausto, nasceu na Alemanha em um acampamento de pessoas desabrigadas. É terapeuta certificado, instrutor e supervisor em Psicodrama, Psychodrama and Intermodal Expressive Arts Therapy Centre (EAT) em Tel-Aviv. Tem ministrado cursos na Europa, nos EUA, no Canadá, na Austrália e em Israel nos últimos 35 anos, bem como lidera grupos de diálogo para israelenses e palestinos. 7 Hatzanhanim Street, Rehovot, 7621107 -Israel. Tel.: Home: +972-8-9458629. Mobile: +972-52-2649155

Hilde Goett (Dipl. Soz. Päd) nasceu na Romênia, neta de membros da SS, cujas esposas foram deportadas para a Sibéria. É instrutora certificada e supervisora de Psicodrama (DGSV) no Psychodrama Institute for Europe (PIfE), bem como presidente desse Instituto. Mora e trabalha em Berlim, Alemanha. É terapeuta de crianças e adolescentes, focando em trauma, violência doméstica e suicídio. Einemstr. 14. 10785, Berlin - Germany. Tel.: Home: +49-302629860. Mobile: $+49-151-50617828$ 